\title{
MEMORIAL SOBRE A TRAJETÓRIA ESCOLAR BÁSICA DE GLÁUCIA MACHADO COSTA
}

Gláucia Machado Costa1

Resumo: O presente texto trata do memorial sobre a trajetória escolar de Gláucia Machado Costa, ex-integrante do Programa Conexões de Saberes. Tem como objetivo apresentar os passos percorridos desde o início da educação básica até a entrada à UFPA e quais os principais entraves de estudantes das comunidades populares adentrarem o ensino superior público. A memória foi usada como principal referência para construção do material. Em seus resultados, apresenta os esforços individual e coletivo para que de fato a educação seja uma questão de direito e não de privilégio de poucos.

\author{
"Minha vida é andar, por este país \\ Pra ver se um dia, descanso feliz \\ guardando a recordação, das terras onde passei \\ Andando pelos sertões, dos amigos que lá deixei \\ Chuva e sol, poeira e carvão \\ Longe de casa, sigo o roteiro mais uma estação \\ E a alegria no coração..." \\ (Luiz Gonzaga)
}

Minha vida sempre foi uma caixinha de surpresas, quando menos esperava uma mudança acontecia, não apenas territorial, mas também mudança de pensamentos e atitudes que foram conseqüências, o crescimento de qualquer ser humano requer busca, e foi esse o ponto de partida de minha história; quero dizer que não mudávamos para fugir, e sim para encontrar algo melhor.

\section{PORTEL - Onde tudo começou \\ Educação Infantil e Ensino Fundamental}

Sou Gláucia Machado Costa, nasci em 12 de janeiro de 1985, no município de Portel. Meus pais se chamam Odete Machado e Francisco Carlos, tenho dois irmãos, Maila e Orleans, e tenho uma sobrinha, Júlia. Até meus 09 anos morávamos nessa cidade, da qual tenho muita saudade, de minha infância, quando podia brincar na rua com meus amiguinhos. $\mathrm{Na}$ escola que estudava, uma coisa muito engraçada acontecia: existia uma cadeirinha que todos queriam sentar-se, mas para isso era preciso chegar bem cedo. Para minha sorte, sempre gostei de estudar e às vezes chorava porque estava doente e não podia ir à escola, era uma das

\footnotetext{
${ }^{1}$ Especialização em Gestão Educacional e Docência do Ensino Superior pela Escola Superior da Amazônia, email: glauciiaalmeida@hotmail.com
}

Revista PET Interdisciplinar e Programa Conexões /UFPA On-line. Ed. Especial - 2017, BELÉM/ PA - ISSN 2447-097X 
primeiras a chegar; só que para poder entrar na escola cedo ou pulávamos o muro ou subornávamos o vigia com cigarro e sempre dava certo. Lembro de um episódio que aconteceu e que marcou bastante: por pura brincadeira de criança, minha prima Stela, que estudava comigo na época e ate hoje é minha amiga, levou pimenta para escola para misturar na sopa, só que uma de nossas colegas pegou a pimenta depois passou a mão no olho, a imagem dela voltando do hospital com o olho coberto por um curativo ainda é bem forte em minha memória. Mas o maior atrativo que a escola me ofereceu foi o primeiro contato com o mundo dos números e das letras.

Toda minha família por parte do meu pai dependia de um comércio que ele administrava, no entanto, nossa fonte de renda acabou tendo que fechar e, dessa forma, tivemos que mudar.

\section{BREVES - Tempos ruins existem para todos}

Ensino Fundamental

Quando chegamos a Breves, a única pessoa que trabalhava era minha mãe, como economista no Hospital Municipal, e também contávamos com a ajuda do que havia sobrado da venda da casa e do comércio. A vida, no entanto, não era fácil, pois para manter três filhos na escola e ainda sustentar a casa, minha mãe trabalhou arduamente e desempenhou muito bem esta tarefa. Agradeço todos os dias por possuir pais tão maravilhosos. Porém as coisas foram ficando mais complicadas, porque meu pai não conseguia emprego.

Um dia, uma tia que mora em Macapá (Tia Naza), irmã de minha mãe, ligou convidando-a para morar na cidade com proposta de emprego para ela e para o meu pai. Ainda desse período em Breves lembro com muito carinho de uma professora, Socorro, que foi com quem comecei de verdade a ter prazer em estudar. Ela era magra, alta e escrevia de um jeito engraçado por ter dedos longos.

MACAPÁ - Família, Amigos, Dificuldades

Ensino Fundamental e Médio

A viagem até Macapá foi muito triste, pois deixar amigos e todo o resto para trás de novo era difícil, tanto que na hora da despedida o porto estava lotado de pessoas que jamais esqueceremos.

Revista PET Interdisciplinar e Programa Conexões /UFPA On-line. Ed. Especial - 2017, BELÉM/ PA - ISSN 2447-097X 
Ainda sim as dificuldades persistiram. Minha mãe trabalhava em um orgão público municipal (SEMOSP) e meu pai era assessor de uma vereadora, da qual guardo uma mágoa muito grande. Havia dias em que chorava ao ver a situação em que meu pai estava de tanto trabalho, perdeu muitos quilos, meu pai acostumado ao batente passou um bom tempo sem trabalho, sendo que desde novo ajudava a sustentar sua casa, e ver ele impotente diante das dificuldades me entristecia. Apesar de tudo, Macapá nos proporcionou conhecer pessoas (vizinhos, colegas de trabalho e da escola) que se tornaram grandes amigos. Nesse período, a pessoa que estava mais próxima de mim era minha prima, Thayane, que também é minha amiga, desde essa época gostávamos de aprontar, como quando o grupo KLB esteve na capital amapaense, até chuva nós pegamos e, para falar a verdade, nem éramos tão fãs assim; ou quando o cantor Cláudio Zoli foi à cidade, até tentar abrir um cadeado com brilho labial, tentamos só para chegar perto dele, me divertia muito. Ainda lá conclui meu ensino médio e prestei o vestibular pela primeira vez para o curso de História na Universidade Federal do Amapá (UNIFAP), mas não passei. Como o emprego dos meus pais tinha vínculo político, acabaram sendo demitidos. O tempo que passamos na cidade foi de grande aprendizagem, pois sentimos o verdadeiro significado de família e união.

\section{BELÉM - Recomeço}

Ensino Superior

Com a esperança de condições melhores, acabamos nos mudando para Belém deixando para trás mais uma vez coisas que construímos, porém nessa mudança minha irmã não nos acompanhou. Ela voltou à Breves por ter passado em um concurso da UFPA, levando consigo uma pequena parte de nós, que considero ser hoje uma das pessoas que amo demais, Júlia. Já em Belém, meus pais ainda não estavam trabalhando, sobrevivíamos com a ajuda de minha irmã e da venda de roupas que minha mãe fazia, tivemos muitos momentos complicados, no entanto estávamos do lado dos nossos familiares que sempre nos apoiaram, o que nos confortava. Nas eleições de 2004 um grande amigo da minha família foi eleito prefeito na nossa terra natal, Portel, e ofereceu emprego para os meus pais. Agradeço todos os dias por esta vitória, não agüentava ver minha família daquela forma e, graças a Deus, meus pais acabaram fazendo um concurso e passaram, minha mãe para professora, e meu pai para motorista de máquinas pesadas. Daquele dia em diante, minha esperança era não ouvir minha mãe pronuciar novamente: estamos ganhando para sobreviver, e não pra viver. Acabei 
ficando em Belém na casa de minha querida avó Stefania e da minha tia Edina, pessoa da qual jamais poderei esquecer, pois enquanto morei em sua casa tive muito incentivo para lutar sempre, correr atras do melhor, tudo através de muito estudo. Nessa época tive meu primeiro contato com uma universidade ainda que fosse particular, no curso de Licenciatura em História na Universidade do Vale do Acaraú (UVA), porém a mensalidade estava muito pesada para o bolso dos meus pais e acabei trancando. Todos os lugares que passamos trouxemos um pouco de cada, e deixamos nossa marca mesmo que humilde.

\section{UNIVERSIDADE FEDERAL DO PARÁ - Um sonho realizado}

Já no final de 2005 recebi a ligação da minha irmã pedindo para eu fazer o vestibular, mas estava sem dinheiro e as inscrições haviam encerrado, mas logo depois eles prorrogaram o prazo e decidi me escrever. Então, minha tia emprestou o dinheiro, só que não tinha o da passagem. Pela manhã, quando voltava da universidade, parei no sinal e quando olhei para meu pé estava um vale-transporte; na hora me subiu até um frio. Cheguei à UFPA cedo, e o movimento era pequeno, pois os servidores estavam em greve; na porta do Daves já havia algumas pessoas esperando para se inscrever. Quando abriu, não sei como fui a segunda da fila, entreguei o comprovante e quando sai o pessoal da greve exigiu que parassem de fazer as inscrições, outro susto que tomei. Ali eu senti que tudo aquilo não estava acontecendo em vão. Fiz as provas, estudando pouco, mas consegui entrar na universidade na qual, quando criança, achava uma conquista impossível, para o curso de Pedagogia intervalar no município de Breves. No dia do resultado estava passeando com meus pais em Portel, e por ser uma cidade pequena os telefonemas para fora não estavam passando. Meu pai ficou sabendo do resultado, pois tinha ouvido no rádio e depois viu pela Internet; ligou-me parabenizando. A felicidade foi tão grande que quase não acreditei, na hora estava sozinha em casa e fui até o trabalho da minha mãe, só que encontrei com ela no caminho. A alegria e a festa foram de toda a família, pois com muito esforço e amor colocavam mais um filho na universidade.

Dessa forma tive que voltar à Breves em junho de 2006para estudar, e acabei morando aqui por trabalhar na universidade, primeiramente como estagiária do Campus de Breves com o PDI, e mais tarde no Programa Conexões de Saberes.

A experiência de estar na universidade e poder conhecer um mundo diferente através das leituras que venho fazendo, contribuem para tornar-me uma cidadã consciente e crítica. Curso o $4^{\circ}$ semestre de Pedagogia, e estou muito satisfeita com o que venho aprendendo. 
CONEXÕES DE SABERES - Olhos atentos, identificação.

Durante minha participação no Conexões pude conhecer uma das cidades mais bonitas do Brasil, o Rio de Janeiro, quando fomos ao Seminário Nacional do Programa Conexões de Saberes, mas a euforia mesmo ficou por conta de poder discutir o acesso e a permanência dos estudantes das camadas populares; isso chamou minha atenção, pois desde o começo acreditei que poderia enriquecer este debate, já que de certa forma me enquadro no perfil do alunado que o programa deseja atingir. Tenho mais de um ano de Conexões e acredito que estar no programa possa ajudar não só a mim, mas outras pessoas que se encontram na mesma condição, com dificuldade para entrar e também permanecer em um curso superior.

As propostas lançadas pelo Programa como o Cursinho Popular, que ajudam pessoas que não têm condições de pagar um cursinho, são muito audaciosas, mas acredito que se não houver o primeiro passo, não saberemos se dará certo, exemplo disso é minha permanência na universidade, pois vim com muita coragem de outra cidade buscar o conhecimento que considero ser uma arma poderosa. No entanto, me manter na universidade tem sido muito difícil, mas a recompensa é tão boa por estar lutando por uma coisa que acredito ser valiosa, que as dificuldades acabam sendo superadas.

No mundo inteiro existem pessoas que têm seus momentos mais complicados, por isso minha família não é a única, mas a mudança existe se tiver fé, foi o que fiz, existem coisas na vida que não vêm fácil, mas se vier, devemos aproveitar o presente de Deus.

A universidade abre um leque muito grande para que se veja o mundo com outros olhos, mas não se pode acomodar só com que se aprende dentro da academia, é preciso ir além, ultrapassar os muros e enxergar a realidade.

Tenho plena convicção de que tudo que venho passando vai valer a pena, e vou poder dizer aos meus filhos e netos que obstáculos vão existir sempre, que às vezes se paga um alto valor por uma conquista. Entretanto, tudo isso se tornará insignificante, depois de um sonho realizado, e que família é a melhor de todas as criações, a minha não é a família perfeita, mas está bem próxima, porque o amor reina em seu meio.

\footnotetext{
Eu sei que os sonhos são pra sempre Eu sei aqui no coração

Eu vou ser mais do que eu sou

Para cumprir as promessas que eu fiz

Porque eu sei que é assim

Que os meus sonhos dependem de mim
}

Revista PET Interdisciplinar e Programa Conexões /UFPA On-line. Ed. Especial - 2017, BELÉM/ PA - ISSN 2447-097X 


\section{Eu vou tentar \\ Sempre \\ E acreditar que sou capaz \\ De levantar uma vez mais \\ Eu vou seguir \\ Sempre \\ Saber que ao menos eu tentei \\ E vou tentar mais uma vez \\ Eu vou seguir}

Não sei se os dias são pra sempre

Guardei você no coração

Eu vou correndo atrás

Aprendi que nunca é demais

Vale a pena insistir

Minha guerra é encontrar minha paz...

(Versão de Marina Elali e Dudu Falcão)

Revista PET Interdisciplinar e Programa Conexões /UFPA On-line. Ed. Especial - 2017, BELÉM/ PA - ISSN 2447-097X 